\title{
Physical after effects and clients satisfaction following colposcopy and cervical biopsy in a Nigerian population
}

\author{
Okonkwo CA, *Ezeanochie MC, Olagbuji BN
}

Department of Obstetrics and Gynecology, University of Benin Teaching Hospital, Benin City, Edo state, Nigeria.

\begin{abstract}
Background: Although Nigeria has a high prevalence of cervical cancer, screening services including colposcopy and directed cervical biopsy are not widely available

Objectives: A prospective study among 111 women who had colposcopy and cervical biopsy following an abnormal Pap smear result at the University of Benin Teaching Hospital in Nigeria. It explored physical after effects experienced and satisfaction of clients after the procedure.

Results: The mean age of the population was $49.5 \pm 8.7$ years (range, $30-64$ years) and majority

$(64.9 \%)$ had tertiary education. Overall, 69 women $(62.2 \%)$ reported physical effects following the procedure. Common physical effects experienced included spotting blood per vaginam $(65.2 \%)$, pain $(34.8 \%)$ and vaginal discharge $(17.4 \%)$. Spontaneous resolution of symptoms occurred within 48 hours in $90.9 \%$ of those who reported physical effects. Clients who experienced physical after effects were significantly older $(p=0.002)$ and had tertiary education $(p=0.019)$. Majority of the women $(94.6 \%)$ were satisfied with the screening services and more than $97 \%$ were willing to accept a repeat procedure. Conclusion: Although majority of the clients who had colposcopy and cervical biopsy reported they experienced physical side effects, more than $97 \%$ were willing to have a repeat procedure. This information can assist colposcopic service providers in counseling clients.
\end{abstract}

Keywords: Cervical cancer, Colposcopy, Physical effects, Satisfaction, Clients, Nigeria African Health Sciences 2013; 13(2): 402 - 406 http:/ /dx.doi.org/10.4314/ahs.v13i2.29

\section{Introduction}

Cervical cancer remains the second commonest cancer among women worldwide and the leading cause of cancer deaths in developing countries. ${ }^{1}$ It is the most common cancer among women in the developing world which accounts for about $85 \%$ of the global burden of cervical cancer. ${ }^{2}$ Unlike developing countries, population based mass screening programs in developed countries have resulted in a massive decline in morbidity and mortality from invasive cervical cancer. ${ }^{3}$

In the developed countries, colposcopy evaluation of the cervix is routinely employed in the assessment, diagnostic workup and subsequent management of women with abnormal screening tests. By contrast, routine cervical cancer screening programs with colposcopy services and published data by colposcopy providers are scarce, particularly
*Corresponding author:
Michael C Ezeanochie
Dept of Obstetrics \& Gynaecology
University of Benin Teaching Hospital
PMB 1018 Benin- City, Edo-State.
Telephone +2348035537234
E-mail: ezemichael75@yahoo.com

in the West Africa sub-region. ${ }^{4}$ Studies have reported the age of the client, level of knowledge about the procedure, sociocultural characteristics and staff attitude at screening centres as factors that can influence the uptake of cervical cancer screening and colposcopy services. ${ }^{5,6,7}$ However, majority of these studies investigated clinical outcomes usually from the perception of the service provider. Indeed, limited studies have reported physical after effects like vaginal bleeding, pain and vaginal discharge following cervical biopsy performed during colposcopy. ${ }^{8}$ Exploring the pattern of side effects and the experience of clients after invasive procedures like colposcopy designed for preventive healthcare, especially among populations where these services are not widely available, provides valuable feedback and data that can facilitate improved service delivery, increased uptake and acceptability of this important procedure. Colposcopic evaluation of the cervix and directed biopsy recently became available in our unit as a routine evaluation for women with abnormal pap smears.

This study was designed to document the experience and the level of satisfaction among clients accessing this relatively new procedure in an environment where the prevalence and mortality 
from cervical cancer is unacceptably high and mass screening programs for the condition is largely nonexistent. This information will assist in expanding access to this intervention in this region and facilitate the establishment of colposcopy services tailored to the needs of the population.

\section{Methods}

The study was conducted at the Gynaecological Oncology unit, Department of Obstetrics and Gynaecology, University of Benin Teaching Hospital, Nigeria from January to December 2010. The hospital serves as a referral centre. Ethical approval for this work was obtained from the institution's ethics and research committee. Women with abnormal cervical cytology are referred to our unit for colposcopic evaluation in a dedicated clinic with trained Consultant gynaecologists, senior registrars and nurses. At first contact, they are routinely counselled on their cytology results, the spectrum of premalignant cervical lesions and its possible progression to invasive cervical cancer. The procedure for colposcopy and its possible physical after effects following biopsy are discussed with every client and the available options of management following a review with the results of histology in 6 weeks are explained.

The procedure was performed in a dedicated private room with a trained female nurse acting as a chaperon.

The study participants were healthy, asymptomatic women who gave consent for the study. In addition they were having their first colposcopic cervical evaluation and presented for the follow-up visit in six weeks after a satisfactory procedure. Each participant had colposcopy and directed biopsy (using cervical biopsy forceps) after the application $5 \%$ acetic acid to the cervix using a cotton swab in a modified lithotomy position. Haemostasis is routinely secured at biopsy points usually with firm pressure or the application of Monsel's paste before the clients are allowed home. Antibiotic prophylaxis is not routinely administered to clients for the procedure.

A structured questionnaire, administered by trained doctors, was used to collect information on the social and demographic characteristics of the participants at the 6th week follow-up visit. Specific clinical variables of interest elicited included the cytological smear abnormality (using the Bethesda system of classification9) requiring referral for colposcopy, interval between smear and colposcopy evaluation, physical after effects like vaginal bleeding or abnormal vaginal discharge observed following colposcopic biopsy and their severity as assessed by the client including the need for medical consultation before the 6th week visit. In addition the client's overall satisfaction with the procedure, the reasons for dissatisfaction and willingness to accept a repeat procedure were evaluated.

A database was generated from the completed questionnaires and the data was analyzed using STATA statistical software, version 12. Categorical variables were analyzed using the Chi square or Fischer exact test, where appropriate, and continuous variables with the two sample $t$ test (unequal variance). Differences were considered significant if $P<0.05$.

\section{Results}

During the study period, 118 women were approached to participate in the study but 7 declined while 111 women $(94.1 \%)$ agreed to participate. The socio-demographic and background clinical characteristics of the participants are presented in table 1.

\section{Table 1: Characteristics of the study population}

\begin{tabular}{|c|c|c|}
\hline Variable & $\begin{array}{l}\text { Number } \\
(\mathrm{N}=111)\end{array}$ & $\begin{array}{c}\text { Percentage } \\
(\%)\end{array}$ \\
\hline $\begin{array}{ll}\text { Mean age } \pm \text { SD } & 49.51\end{array}$ & $1 \pm 8.65$ & - \\
\hline \multicolumn{3}{|l|}{ Level of education } \\
\hline None & 6 & 5.4 \\
\hline Primary & 28 & 25.2 \\
\hline Secondary & 6 & 5.4 \\
\hline Tertiary & 71 & 64 \\
\hline \multicolumn{3}{|l|}{ Religion } \\
\hline Christian & 99 & 89.2 \\
\hline Muslim & 12 & 10.8 \\
\hline $\begin{array}{l}\text { Median parity } \\
\text { (range) }\end{array}$ & $4(0-8)$ & - \\
\hline \multicolumn{3}{|c|}{ Cervical cytological abnormality } \\
\hline Inflammatory /Cervicitis & is 8 & 7.3 \\
\hline ASCUS & 15 & 13.5 \\
\hline LGSIL & 35 & 31.5 \\
\hline HGSIL & 55 & 49.6 \\
\hline
\end{tabular}


The mean age of the population was 49.5$\} 8.7$ years (range, $30-64$ years) and majority $(64.9 \%)$ had a tertiary level of education. The commonest cervical cytological abnormality was low grade squamous intra-epithelial lesion (51.4\%). Although the median parity was 4 (range, $0-8$ ), further analysis revealed that 45 respondents $(40.5 \%)$ have had 5 or more deliveries (e"Para 5).

Overall, 69 women $(62.2 \%)$ reported physical effects following colposcopy and cervical biopsy while $42(37.8 \%)$ reported no complaints. Of the 69 women reporting physical effects, the commonest symptoms were vaginal bleeding (spotting) in 45 women (65.2\%), pain in 24 women $(34.8 \%)$ and vaginal discharge by 12 women (17.4\%). These symptoms resolved within 48 hours in 60 women $(90.9 \%)$ while $66(95.7 \%)$ felt the symptoms were not serious and 1 woman $(1.5 \%)$ received medical consult for persistent vaginal discharge which required antibiotic therapy.

In table 2, the characteristics of respondents who reported experiencing physical after effects following colposcopy is compared to the participants who did not. Women who reported experiencing physical after effects were significantly older $(\mathrm{p}=0.002)$ and with tertiary level of education $(\mathrm{p}=0.019)$.

There was no significant difference between both groups in terms of parity, type of cytological abnormality requiring colposcopy and the interval between the Pap smear and colposcopic biopsy. Majority of the women (94.6\%) were satisfied with the procedure while 108 women $(97.3 \%$ ) willing to accept a repeat of the procedure. Of the 7 women who reported non-satisfaction, 4 (57.14) cited the 6 week delay before obtaining the result of histological and then definitive treatment as the commonest reason for non-satisfaction.

Table 2: Characteristics of clients who experienced physical after effects following colposcopic cervical biopsy compared to those who did not

\begin{tabular}{|c|c|c|c|}
\hline Variable & $\begin{array}{l}\text { Experienced physical } \\
\text { effects } N=69(\%)\end{array}$ & $\begin{array}{c}\text { No physical } \\
\text { effects } N=42(\%)\end{array}$ & $P$ value \\
\hline Overall age, years (mean \pm SD) & $47.91( \pm 9.10)$ & $52.94( \pm 7.43)$ & 0.002 \\
\hline \multicolumn{4}{|l|}{ Parity } \\
\hline Nullipara & $4(5.8)$ & $3(7.1)$ & 0.77 \\
\hline Multipara & $65(95.2)$ & $39(92.9)$ & $\mathrm{X} 2=0.08$ \\
\hline \multicolumn{4}{|l|}{ Level of education } \\
\hline None & $3(4.4)$ & $3(7.1)$ & 0.019 \\
\hline Primary & $12(17.4)$ & $16(38.1)$ & $\mathrm{X} 2=7.91$ \\
\hline Secondary & $3(4.4)$ & $3(7.1)$ & \\
\hline Tertiary & $51(73.8)$ & $20(47.7)$ & \\
\hline \multicolumn{4}{|l|}{ Cervical Cytological abnormality } \\
\hline Inflammatory changes & $3(5.8)$ & $4(9.5)$ & 0.32 \\
\hline ASCUS & $12(18.8)$ & $2(4.8)$ & $\mathrm{X} 2=2.27$ \\
\hline LGSIL & $18(25.5)$ & $16(38.1)$ & \\
\hline HGSIL & $33(47.9)$ & $20(47.6)$ & \\
\hline $\begin{array}{l}\text { Interval between pap smear and } \\
\text { colposcopy in weeks (mean } \pm S D)\end{array}$ & $19.30( \pm 16.52)$ & $16.50( \pm 14.62)$ & 0.35 \\
\hline \multicolumn{4}{|l|}{ Level of satisfaction } \\
\hline Satisfied & 63(91.3) & $36(85.8)$ & 0.55 \\
\hline Indifferent & $2(2.9)$ & $3(7.1)$ & $\mathrm{X} 2=1.21$ \\
\hline Not satisfied & $4(5.8)$ & $3(7.1)$ & \\
\hline \multicolumn{4}{|c|}{ Acceptance of repeat colposcopy and biopsy } \\
\hline Yes & 68(98.6) & $40(95.2)$ & 0.297 \\
\hline No & $1(1.4)$ & $2(4.8)$ & $\mathrm{X} 2=1.09$ \\
\hline
\end{tabular}




\section{Discussion}

The satisfaction with colposcopy and cervical biopsy by majority of the participants in our data suggest that these procedures can be offered together in cervical cancer screening programs in our setting. A previous study has suggested that non-compliance with colposcopy clinic appointments may be due to patient non-satisfaction with the service ${ }^{10}$. Although more than $60 \%$ of participants reported experiencing physical after effects, 95\% expressed satisfaction with colposcopy evaluation with cervical biopsy. The high satisfaction of clients may partly be explained by the fact that the study was in a university Teaching Hospital setting with trained personnel and the preprocedure counselling the clients routinely receive.

Majority of the clients were educated with more than two thirds having secondary or tertiary school education. This suggests that female education may play a role in accessing and utilising cervical cancer screening services. The women who accessed the service were mainly of advanced maternal age and multiparous with previous deliveries. High maternal parity has been recognised as an epidemiological risk factor associated with cervical cancer ${ }^{11,12}$. It is therefore not surprising that multiparous women (at increased risk of cervical cancer) comprised over $90 \%$ of the study population with $40 \%$ having 5 or more previous deliveries.

The pattern of physical effects reported by the women is comparable to previously published data by Sharp et al among a predominantly Caucasian population ${ }^{8}$. Vaginal bleeding, abnormal vaginal discharge and pain after colposcopy and cervical biopsy were the common effects reported in this study.

Despite the experience of the downsides of the procedures by about two-thirds of our study participants, a higher proportion of our study population considered these effects not to be serious. The vaginal bleeding was limited to spotting (mild) and stopped within 48 hours in most women while only one woman with vaginal discharge required antibiotic therapy. However, it is important when preparing women for the procedure to counsel them of the potential occurrence of minor physical effects noted in the present study. This may reduce undue anxiety, improve their overall satisfaction with the procedure, and enhance the uptake of the cervical cancer screening services, particularly in resource constrained countries with high burden of cervical cancer.
Women who reported that they experienced physical effects following colposcopy and cervical biopsy were significantly younger and had tertiary level of education compared to those who did not experience physical after effects. A possible explanation for the association between educational status and report of symptoms is that more educated clients are more likely to report any adverse effects observed to health providers following a procedure. The finding of the significant association between age and report of physical effects following colposcopy and biopsy should stimulate further studies on this issue. This study does have some limitations. The relatively small sample size and the setting for the study in a Teaching Hospital require some caution in extrapolating the findings to the general population.

It however provides relevant information on a service that is still not readily available in our subregion

with very limited published African data.

\section{Conclusion}

Our study shows routine colposcopy and directed cervical biopsy can be offered in a resource limited setting in the West African sub region with satisfactory outcome. Although majority of the clients report experiencing physical side effects like minor vaginal spotting, pain or vaginal discharge, they were still willing to accept a repeat procedure. This information can assist in the design of client friendly cervical cancer screening programs to enhance uptake by women who require this service ultimately reducing the unacceptably high prevalence of cervical cancer in our region with its associated morbidity and mortality.

\section{References}

1. Arbyn M, Sankaranarayanan R, Muwonge R, Keita N, Dolo A, Mbalawas CG et al. Pooled analysis of the accuracy of five cervical cancer screening tests assessed in eleven studies in Africa and India. Int J Cancer. 2008;123(1): 153-160.

2. Anorlu RI. Cervical cancer: The sub-Saharan African perspectives. Reprod Health Matters. 2008; 16(32): 41-9.

3. Franco EL, Coutlee F, Ferenczy A.Integrating human papillomavirus vaccination in cervical cancer control programmes. Public Health Genomics. 2009;12(5-6):352-61.

4. Muwonge R, Mbalawa CG, Keita N, Dolo A, Nouhou H, Nacoulma M, et al. IARC Multicentre 
Study Group on Cervical Cancer Early Detection. BJOG. 2009; 116(6): 829-37.

5. Arrossi S, Ramos S, Paolino M, Sankaranarayanan R.Social inequality in Pap smear coverage: identifying under-users of cervical cancer screening in Argentina. Reprod Health Matters. 2008;16(32):50-8.

6. Sanders G, Craddock C, Wagstaff I.Factors influencing default at a hospital colposcopy clinic. Qual Health Care. 1992;1(4):236-40.

7. Swancutt DR, Greenfield SM, Wilson S.Women's colposcopy experience and preferences: a mixed methods study. BMC Womens Health. 2008;14;8:2.

8. TOMBOLA (Trial Of Management of Borderline and Other Low-grade Abnormal smears) Group, Sharp L, Cotton S, Cochran C, Gray N, Little J et al. After-effects reported by women following colposcopy, cervical biopsies and LLETZ: results from the TOMBOLA trial BJOG.2009;116(11):1506-14.

9. Solomon D, Davey D, Kurman R, Moriarty A, O'Connor D, Prey M, et al. The 2001 Bethesda System: terminology for reporting results of cervical cytology. JAMA. 2002;287:2114-9.

10. Patterson T, Roworth M, Hill M: An investigation into the default rate at the Fife colposcopy clinic: implications for target setting. Journal of Public Health Medicine 1995, 17:65-69

11. Munoz N, Franceschi S, Bosetti C, et al. Role of Parity and Human Papillomavirus in Cervical Cancer: The IARC Multicentric Case-Control Study. Lancet. 2002;359:1093-1101

12. Adewuyi SA, Shittu SO, Rafindadi AH. Sociodemographic and clinicopathologic characterization of cervical cancers in northern Nigeria.Eur J Gynaecol Oncol. 2008;29(1):61-4 